\title{
Cheiloscopy an Unfolding Tool
}

\section{Iqra Khilji', Rosheni Ann Mamen' ${ }^{2}$, Avineet Kaur ${ }^{3}$, Shalika ${ }^{4}$, Harnoor \\ Iqra Khilji', Rosheni Ann Mamen ${ }^{2}$, Avineet Kaur ${ }^{3}$, Shalika $^{4}$, Harnoor
Singh Sandhu ${ }^{5 *}$ and Mehraab Dhillon}

\author{
${ }^{1}$ Medical Officer (Dental), Hazrat Haleema Maternity and General Hospital \\ Garewal chowk, Malerkotla, Punjab, India \\ ${ }^{2}$ Periodontist, Private Practitioner, Multispeciality Dental Care Center, Trissur, \\ Kerala, India \\ ${ }^{3}$ Senior Lecturer, Department of Periodontology and Oral Implantology, Swami \\ Devi Dyal Dental College and Hospital Golpura, Barwala, Haryana, India \\ ${ }^{4} J u n i o r$ Resident, Department of Dermatology, Gian Sagar Medical Hospital Banur, \\ Rajpura, Punjab, India \\ ${ }^{5}$ Emergency Medical Officer, Department of Emergency, Gian Sagar Medical \\ Hospital Banur, Rajpura, Punjab, India \\ ${ }^{6} 3^{\text {rd }}$ Prof Student, SKSS Dental College, Ludhiana, Punjab, India \\ *Corresponding Author: Harnoor Singh Sandhu, Emergency Medical Officer, \\ Department of Emergency, Gian Sagar Medical Hospital Banur, Rajpura, Punjab, \\ India.
}

Received: September 03, 2021

Published: September 11, 2021

(C) All rights are reserved by Harnoor Singh

Sandhu., et al.

\section{Abstract}

Forensic odontology is a branch of forensic sciences which uses the skill of the dentist as well as forensic odontologist to use dental records in personal identification in various legal purposes. This needs various distinctive and less familiar techniques and cheiloscopy technique is one of them. Cheiloscopy is acquired from ancient Roman words cheilos-lips and skopein-study. Thus, cheiloscopy is defined as the study of lip prints. It facilitates the human identification on the bases of lip traces/designs in various legal purposes. It is used as an accessory tool in crime investigation and used in sex determination, racial determination etc. Like finger prints of a human, the lip patterns are also unique and different in every person. The present review highlights on chiloscopy.

Keywords: Cheiloscopy; Forensic; Lip Prints; Personal Identification

\section{Introduction}

The individual is defined by the group of somatic, practical or intellectual, usual or clinical characteristics -which gives us the concept of "identity" [1-3]. Human's identification is based upon scientific postulates and has always been a way of inconvenience for scientists in early times [2,3]. The tools used for identification of humans are DNA analysis, anthropometry, dental data and fingerprints. Along with all these tools a new tool for personal identification evolved is cheiloscopy [2]. Among all these, the study of lip prints and fingerprints are the least invasive and cost-efficient methods for identification [4]. 
Cheiloscopy is acquired by two Ancient Roman words 'cheilos'lips and 'skopein-study' [1,4-7]. The characteristic pattern of elevations and depressions (i.e. crinkles and fissures) on mucosal membrane of lips called as "sulci labiorum rubrorum" make a special design on lips and investigation of these designs on lips is named as cheiloscopy (Figure 1) [2,3,7-11]. Cheiloscopy is used as an evidence based inspection method which deals with human recognition based on drafts of lip designs [12]. Like finger patterns 'lip prints are also distinctive for a person $[1,6,10]$. It act as anatomical character of human identification and sex determination. [1,2]. Lip designs are evident very soon i.e. in one and half month of embryo in womb of mother and won't modify throughout whole lifespan of a human $[1,6,8,11]$. These white areas seemed in lip prints are the creases on the vermilion border of the lips and the dark areas are the raised red areas outlined by creases, are similar to the furrows and ridges of friction ridge skin [9].

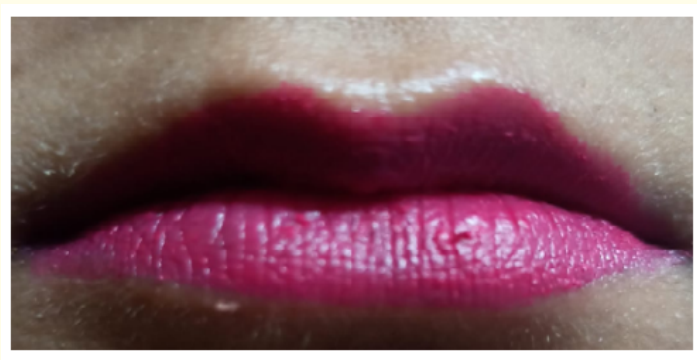

Figure 1: Anatomy of lips.

Lip patterns are unique, permanent, unchangeable i.e. they resist adversity and recovers from inflammations, trauma and diseases like herpes or any environmental changes: all these makes lip print a potent and immaculate tool in identification process. Lip prints are used as an adjunct tool at the site of crime to verify absence or presence of a person $[1,6,10,12]$.

Apart from serving society by clinical observations, inquiring, detecting and treating ailments of oral cavity, the professional ethics of dental surgeon is to participate in other communal and licit affairs as well [1].

Lips are very delicate in nature. These sessile structures are comprised of skin, mucous membrane, glands and muscles. The upper lip is called as labium superior oris and the lower lip is known as labium inferius oris. Lips forms anterior boundary of the oral cavity and surround the oral orifice. Morphologically the structure that make oral sphincter whether it is enveloped with skin or mucosa, is area of lip. The upper lip lies between the nose and oral cavity i.e. lies under the nose; extends from the nasolabial folds laterally towards the cheek. The upper lip is characterized by the philtrum; a central depression presents directly below the nasal septum. Upper and lower lips are subdivided as mentioned in figure 2. The lower lip comprises the region between the lateral commissures and the labiomental crease of the chin. The corners of mouth are known as commissures. The two lips joined at commissures and are separated by buccal fend. Lips play a vital role in various functions such as drinking, eating facial expression, phonation, intimacy and physical attraction $[8,9,11,13]$.

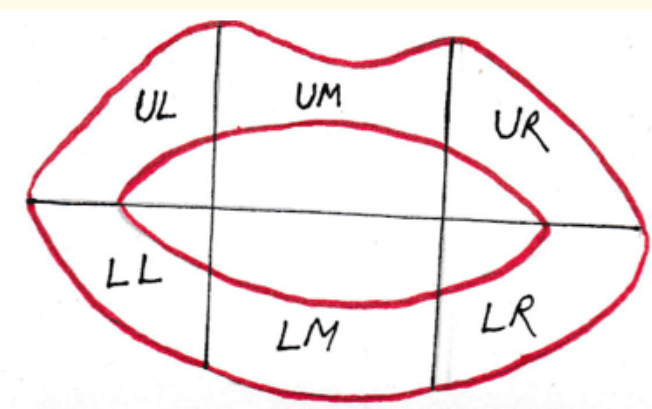

Figure 2: Parts of lip.

ULL: Upper Left Lip; LLL: Lower Left Lip; UML: Upper Middle Lip; LML: Lower Middle Lip; URL: Upper Right Lip; LRL: Lower Right Lip.

History $[1,2,5,8,12]$

\begin{tabular}{|c|c|cl|}
\hline Year & Contibutor & \multicolumn{1}{c|}{ Contribution } \\
\hline 1902 & R. Fischer & $\begin{array}{l}\text { He first noted the Biological } \\
\text { phenomenon of systems of fur- } \\
\text { rows on the red part of human } \\
\text { lips. }\end{array}$ \\
$\begin{array}{c}\text { (Anthropolo- } \\
\text { gist) }\end{array}$ & $\begin{array}{ll}\text { He also described grooves on } \\
\text { upper and lower lips }\end{array}$ \\
\hline
\end{tabular}




\begin{tabular}{|c|c|c|}
\hline 1932 & \begin{tabular}{|c|} 
Edmond \\
Lockard \\
(France's \\
Criminologist)
\end{tabular} & $\begin{array}{l}\text { - Recommended the use of print } \\
\text { for identification of a person in } \\
\text { crime investigation }\end{array}$ \\
\hline 1950 & $\begin{array}{l}\text { La Moyne (The } \\
\text { Father of } \\
\text { Cheiloscopy) }\end{array}$ & $\begin{array}{l}\text { - In his book labeled as "HOMI- } \\
\text { CIDE INVESTIGATION “he said } \\
\text { that as finger prints lips also } \\
\text { posses distinctive lip prints for } \\
\text { each and every person. }\end{array}$ \\
\hline 1960 & $\begin{array}{l}\text { Dr. Martin } \\
\text { Santos }\end{array}$ & $\begin{array}{l}\text { - Narrates how lip prints unique } \\
\text { feature can be used for identifi- } \\
\text { cation of a person } \\
\text { - } \begin{array}{l}\text { Presented his own classifica- } \\
\text { tion of lips. }\end{array}\end{array}$ \\
\hline $\begin{array}{l}1968- \\
1971\end{array}$ & $\begin{array}{l}\text { Kazuo Suzuki } \\
\text { Yasuo Tsuchi- } \\
\text { hashi }\end{array}$ & $\begin{array}{l}\text { - Found that lip prints of identi- } \\
\text { cal twins were different. } \\
\text { - They gave their their own } \\
\text { classification which stated that } \\
\text { lips have six different types of } \\
\text { grooves. }\end{array}$ \\
\hline 1981 & Cottone & $\begin{array}{l}\text { - He mentioned in his book titled } \\
\text { as "OUTLINE OF FORENSIC } \\
\text { DENTISTRY" that cheiloscopy } \\
\text { as one of special techniques } \\
\text { individualization. }\end{array}$ \\
\hline 2000 & Vahanwala & $\begin{array}{l}\text { - Conducted various studies to } \\
\text { promote the cheiloscopy in } \\
\text { forensic science }\end{array}$ \\
\hline
\end{tabular}

Table 1

\section{Classification $[1,5,9,12]$ :}

1. Clauco Martin Santos lip print classification: Dr. Santos was first person who gives classification of lips based on nature of wrinkles and grooves into two main types which are further subdivided into groups as shown in table 2 .

\begin{tabular}{|l|l|}
\hline \multicolumn{1}{|c|}{ (A) Simple } & (B) Composite \\
\hline a. Straight line & a. Bifurcated \\
\hline b. Curved line & b. Trifurcated \\
\hline c. Angled line & c. Anomalous \\
\hline d. Sign like curve & \\
\hline
\end{tabular}

Table 2

\section{Suzuki's and Tsuchihashi's lip print classification:(1970)} they classify the lip designs on basis of form and route of the furrows and is divided into six types as shown in table 3 and figure 3.

\begin{tabular}{|l|c|}
\hline Type I & $\begin{array}{c}\text { A definite streak or furrow runs in upright } \\
\text { direction over the entire lip }\end{array}$ \\
\hline Type I & $\begin{array}{c}\text { Straight furrow which disappear half } \\
\text { way rather than enveloping the whole } \\
\text { thickness of the lip or half-extent furrow } \\
\text { of type I }\end{array}$ \\
\hline Type II & $\begin{array}{c}\text { Fork furrows in their route or subdivided } \\
\text { furrows or branched y pattern }\end{array}$ \\
\hline Type III & Intersecting grooves \\
\hline Type IV & Reticulate grooves \\
\hline Type V & Undermined \\
\hline
\end{tabular}

Table 3
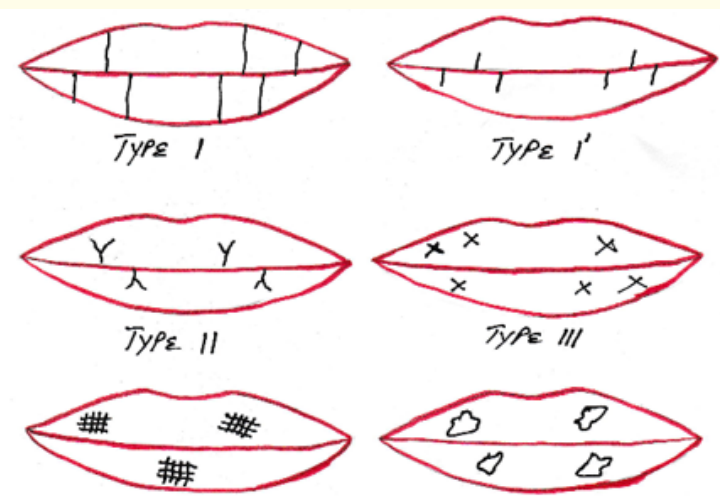

Figure 3: Classification of lip designs.

3. Raynaud's Classify lip designs as follow: Table 4 .

4. Afchar-Bayat's Classification (1979): Table 5.

5. Vahanwala., et al. classification: He suggested that some design were prevailing in either sex as shown in given table 6.

6. Classification of lips based on thickness: Table 7. 


\begin{tabular}{|l|c|}
\hline Type A & Complete Vertical \\
\hline Type b & Incomplete vertical \\
\hline Type c & Complete bifurcated \\
\hline Type d & Incomplete bifurcated \\
\hline Type e & Complete branched \\
\hline Type $\mathrm{f}$ & Incomplete branched \\
\hline Type g & Reticular pattern \\
\hline Type h & X or coma form \\
\hline Type i & Horizontal \\
\hline Type $\mathrm{j}$ & Other forms (ellipse, triangle). \\
\hline
\end{tabular}

Table 4

\begin{tabular}{|l|c|}
\hline A 1 & Vertical and straight grooves, covering the whole lip \\
\hline A 2 & $\begin{array}{r}\text { Vertical and straight grooves, but not covering the } \\
\text { whole lip }\end{array}$ \\
\hline B 1 & Straight-branched grooves \\
\hline B 2 & Angulated-branched grooves \\
\hline C & Converging grooves \\
\hline D & Reticular pattern grooves \\
\hline E & Other grooves \\
\hline
\end{tabular}

Table 5

\begin{tabular}{|l|c|c|}
\hline Lip Pattern & Site & Gender \\
\hline Type & Predilection & Predilection \\
\hline Type I and I' & Quadrant & Female \\
\hline Type II & Second quadrant & Male \\
\hline Type III & $\begin{array}{c}\text { Never occurs in lower } \\
\text { lip }\end{array}$ & If so, only in males \\
\hline $\begin{array}{l}\text { Varied } \\
\text { pattern Type }\end{array}$ & In all quadrant & Male \\
\hline $\begin{array}{l}\text { Similar } \\
\text { pattern Type }\end{array}$ & In all quadrant & Female \\
\hline
\end{tabular}

Table 6

\begin{tabular}{|l|}
\hline Thin lips (common in European Caucasians \\
\hline Medium lips (most common type) \\
\hline Thick or very thick lips (seen in blacks) \\
\hline Mix lips (usually seen in orientals) \\
\hline
\end{tabular}

Table 7
7. As for the basis of the classification, only $10 \mathrm{~mm}$ wide portion of the middle part of the lower lip was taken and illustrated as follow:

a. Linear "L" - if the lines prevail

b. Bifurcation " $\mathrm{R}$ " - if the bifurcation is dominant

c. Reticular "S" - if the lines cross

d. Undermined "N" - when no superiority can be established.

8. Kasprzak's classification: Figure 4.

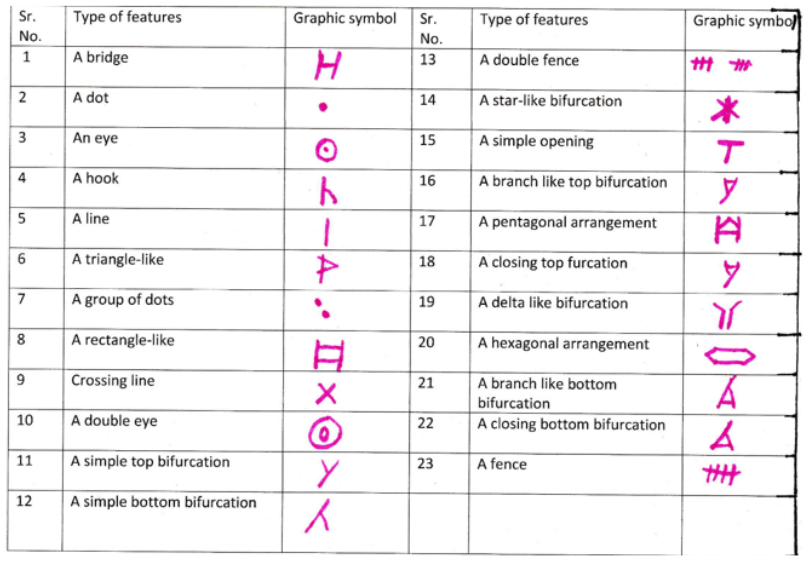

Figure 4: Kasprzak classification of lip designs.

\section{Method for tracing lip prints}

The lips should be cleaned first. Then concerned person is commanded to separate the lips while maintaining distance between two lips and uniform application is being done by a lip brush. Now lips should be gently rubbed together uniformly. The lips color is permitted to dried approximately for 2 to $3 \mathrm{~min}$., now lip designs are drafted on a piece of white bond paper. Serial number is assigned to an individual to reduce confusion [14-16].

\section{Scope of cheiloscopy}

The distinctive characteristics of the lip design assist in recognition of a person as lip prints are not same in humans. Whenever a lip design is detected at the site of an offence, the incident is being identified, people involved, habits, cosmetics used, sexes, occupa- 
tion and the pathological changes of lips and various other activities [12].

\section{Clues detected by cheiloscopy}

- Age determination: Age changes like immaturity of lips in younger age while maturity of lips in older age and loss of anatomic details and tonicity thereby making the identification of age [17].

- Sex determination: Achievement of a fair degree of accuracy in sex determination, in a legal cases, although the difference between positive and negative identification means the difference between the life and death of an individual so, the results in sex determination do not prove ours to be a foolproof method but it takes us one step closer to the truth [16].

- Racial determination: Lip print pattern has a significant difference interracially. So, it could be helpful only as a supplementary tool for individual investigations because of their uniqueness in spite of its limitations [18].

- Crime detection: Many examinations have been done which are revealed on the surface of windows, doors, glasses, cups, bags, and cigarette ends. Most frequently found in the scene of murders, rapes, and burglaries [5].

Now question arises if lipstick is not applied and there are not lip prints then it has been observed that the vermillion border of the lips has minor salivary and sebaceous glands, which, leads to the possibility of the existence of latent lip prints. The identification of latent print evidence is often considered the key in solving a crime [16].

\section{Merits of lip prints}

- Lip prints remain stable over a period of time.

- Lip print also plays a role in sagittal jaw relation as a marker.

- Lip prints are also used to determine age, gender and race of individual.

\section{Demerits of lip prints}

- Soft tissue changes after death so lip prints should be taken within 24 hours of death.

- Position of mouth i.e. close and open mouth position alter lip prints.

- $\quad$ Pathology may alter lip print.

\section{Conclusion}

Lip prints are unique for every individual as like fingerprints. Analysis of lip print is least invasive and cost-effective. Lip prints can be used to determine the age, sex, race of a person and also helps in crime detection. Hence lip prints helps in human identification. Cheiloscopy can be used as adjunct tool for identification purposes in forensic science. The unique characteristic of lip print should be attributed. Despite of all available literature and uniqueness of lip prints, further inquiries should be conducted which includes limitations of lip prints and to overcome it.

\section{Bibliography}

1. Nalliapan G., et al. "Cheiloscopy: An evolving tool in forensic identification". Journal of Indian Academy of Dental Specialist Researchers 5 (2018): 37-41.

2. Bhargava A., et al. "Cheiloscopy-A Novel Tool for Personal Identification and Sex Determination". Saudi Journal of Oral and Dental Research 4.3 (2019): 151-154.

3. Dineshshankar J., et al. "Lip prints: Role in forensic odontology". Journal of Pharmacy and Bioallied Sciences 5.1 (2013): 95-97.

4. Tandon A., et al. "Estimation of gender using cheiloscopy and dermatoglyphics". National Journal of Maxillofacial Surgery 8.2 (2017): 102-105.

5. Kannan S., et al. "Cheiloscopy - A vital tool in crime investigation". International Journal of Forensic Science and Pathology 3.3 (2015): 89-93.

6. Sultana Q., et al. "Cheiloscopy: A scientific approach for personal identification". International Journal of Anatomy and Research 2.4 (2014): 668-672.

7. Kundu S., et al. "Cheiloscopy - A diagnostic and deterministic mirror for establishment of person identification and gender discrimination: A study participated by Indian Medical students to aid legal proceedings and criminal investigations". Journal of Experimental and Clinical Anatomy 15.1 (2016): 3142.

8. Kaushal A and Pal M. "Cheiloscopy: A Vital Tool in Forensic Investigation for Personal Identification in Living and Dead

Citation: Harnoor Singh Sandhu., et al. “Cheiloscopy an Unfolding Tool”. Acta Scientific Dental Sciences 5.10 (2021): 23-28. 
Individuals". International Journal Of Forensic Odontology 5.2

(2020): 71-74.

9. Singh YK., et al. "New Insights of Cheiloscopy". Annals of International Medical and Dental Research 3.3 (2017): 11-15.

10. Aditi S., et al. "Cheiloscopy: Association of lip prints in different skeletal malocclusions". International Journal of Orthodontic Rehabilitation 10.4 (2019): 156-160.

11. Sharma BS., et al. "Cheiloscopy: A tool for antemortem identification”. Indian Journal of Dental Sciences 9.3 (2017): 176-180.

12. Prabhu RV., et al. "Cheiloscopy: Revisited". Journal of Forensic Dental Sciences 4.1 (2012): 47-52.

13. Piccinin MA and Zito PM. "Anatomy, Head and Neck, Lips". Treasure Island (FL) (2020).

14. Kumar A., et al. "Importance of Cheiloscopy". International Journal of Oral Care and Research 4.1 (2016): 48-52.

15. Venkatesh R and David MP. "Cheiloscopy. An aid for personal identification”. Journal of Forensic Dental Sciences 3.2 (2011): 67-70.

16. Ramakrishnan P., et al. "Assessment of cheiloscopy in sex determination using lysochrome- A preliminary study". Journal of Forensic Dental Sciences 7.3 (2015): 195-200.

17. Randhawa K., et al. "Study of the effect of age changes on lip print pattern and its reliability in sex determination". Journal of Forensic Odonto-Stomatology - IOFOS 29.2 (2011): 45-51.

18. Kumar LB., et al. "Reliability of lip prints in personal identification: An inter-racial pilot study". Journal of Forensic Dental Sciences 8.3 (2016): 178.

\section{Volume 5 Issue 10 October 2021}

(C) All rights are reserved by Harnoor Singh Sandhu., et al. 